\title{
EFFECT OF THE VENOM OF GLYCERA CONVOLUTA ON THE SPONTANEOUS QUANTAL RELEASE OF TRANSMITTER
}

\author{
R. MANARANCHE, M. THIEFFRY, and M. ISRAEL \\ From the Départements de Biophysique et de Neurochimie, Laboratoire de Neurobiologie Cellulaire \\ du Centre National de la Recherche Scientifique, 91190 Gif-sur-Yvette, France
}

\begin{abstract}
A neurotoxin able to increase the spontaneous release of transmitter was found in the venom glands of the polychaete annelid Glycera convoluta. We studied the effect of this venom on the frog cutaneous pectoris muscle, where its application produced a prolonged (20-h), high-frequency discharge of miniature potentials. After $5 \mathrm{~h}$ of action, the initial store was renewed several times but no detectable ultrastructural changes were observed. After $19 \mathrm{~h}$ of sustained activity, nerve terminals with their normal vesicular contents were infrequent; others were fragmented and contained swollen mitochondria, abnormal inclusions, and vesicles of various sizes.

In the noncholinergic crayfish neuromuscular preparation, the venom triggered an important increase in spontaneous quantal release that subsided in $1 \mathrm{~h}$. An activity higher than that in resting conditions then persisted for many hours. This high electrical activity was not accompanied by any detectable structural modifications after $3 \mathrm{~h}$.

In the torpedo electric organ preparation, the venom elicited a burst of activity that returned to control levels in $1 \mathrm{~h}$. The release of $\mathrm{ACh}$ (evaluated by the efflux of radioactive acetate) paralleled the high electrical activity. No morphological changes or significant depletion of tissue stores were detected. The venom of Glycera convoluta appears to enhance considerably the release of transmitter without impairing its turnover. The venom effect is $\mathrm{Ca}^{++}$dependent and reversible by washing, at least during the first hour of action.

Because the high rate of transmitter release appears dissociated from the lateroccurring structural modifications, it is possible that the venom mimics one component of the double mode of action proposed for black widow spider venom.
\end{abstract}

Much new information about the physiology of synapses has been obtained by studying the effect of neurotoxins. Among these toxins, black widow spider venom (BWSV $[8,25,7,23,9]$ ), $\beta$-bungar- otoxin (5, 1), and Red Sea flatfish Pardachirus toxin (31) appear to be powerful and valuable tools for the study of presynaptic mechanisms.

A common effect of these presynaptic toxins is 
to induce a tremendous increase in the frequency of miniature potentials and important ultrastructural changes of nerve terminals.

The polychaete annelids Glycera dibranchiata $(18,24)$ and Glycera convoluta $(27)$ have associated with their jaws, four small glands containing a toxic substance. The toxicity of this substance (at least in the case of $G$. convoluta) is slight for man, an accidental contact with skin producing only a local epidermal reaction. However, when injected into the coelomic cavity of crabs, the venom rapidly kills them. We therefore looked for a possible neurotoxicity of this substance. An important increase in the frequency of miniature potentials was indeed found after its application. The first experiments were carried out on neuromuscular preparations of crayfish that are similar in many respects to other crustacean neuromuscular preparations. The effect, however, was not specific for crustacean preparations. Similar effects were obtained with either frog neuromuscular preparations or torpedo electric organs.

We report here that venom of Glycera, which triggers an important and sustained increase in the frequency of miniature potentials, does not induce ultrastructural changes after the release of several times the initial store; modifications are observed only after very long incubations. In this respect, it differs from the presynaptic venom previously cited and may be an interesting tool to use for the further characterization of the release process.

\section{MATERIALS AND METHODS}

\section{Preparation of the Venom Extract}

Glycera convoluta (Keferstein) were collected on the seashore near the Marine Biological Station of Roscoff (France).

After section of the prostomium, the anterior part of the digestive tract was pulled out by means of forceps, and the venom gland complex was removed. The glandular regions of five animals ( 20 glands) were homogenized at $0^{\circ} \mathrm{C}$ in $1 \mathrm{ml}$ of $10 \mathrm{mM}$ sodium phosphate buffer $(\mathrm{pH} 7.2)$ in a small glass-glass handoperated homogenizer. The homogenate was centrifuged at $10,000 \mathrm{~g}$ for $10 \mathrm{~min}$ and the supernate was collected. This solution was generally used immediately after preparation by diluting it with physiological solution. However, no detectable loss of activity was noticed after storage of the concentrated venom solution up to $8 \mathrm{~d}$ at $4^{\circ} \mathrm{C}$. It was also found that the glands could be kep at $-80^{\circ} \mathrm{C}$ for several months without any loss of activity. Unless otherwise specified, the crude extract was used.

In some experiments, the crude extract was gel filtered. We passed $0.5 \mathrm{ml}$ of extract of venom through a $5-\mathrm{ml}$ column of Sephadex G-50 (coarse) equilibrated with Ringer's solution. This permitted collection (in $1 \mathrm{ml}$ of Ringer's) of the venom that was found in the void volume.

\section{Preparations and Solutions}

FROG: The cutaneous pectoris muscle of Rana esculenta was dissected and soaked in Ringer's solution (in $\mathrm{mM}: \mathrm{NaCl}$ 110; $\mathrm{KCl}, 2.14 ; \mathrm{CaCl}_{2}, 1.14 ; \mathrm{NaHCO}_{3,}, 0.59$; adjusted to $\mathrm{pH} 6.7$ ). Experiments were carried out at room temperature $\left(18^{\circ}-22^{\circ} \mathrm{C}\right)$.

CRAYFISH: Two different neuromuscular preparations of Procambarus clarkii were used. One was the posterior fast abdominal flexor (30), which was dissected from the 2 nd or 3 rd abdominal segment. The other preparation was the opener of the dactyl from the 1 st or 2 nd walking leg (extensively used since the work of Dudel and Kuffler [10]). The preparations were soaked in Van-Harreveld solution (in $\mathrm{mM}: \mathrm{NaCl}, 195 ; \mathrm{KCl}, 5.4 ; \mathrm{CaCl}_{2}$, 13: $\mathrm{MgCl}_{2}, 2.6$ : Tris-maleate buffer, 10 ; adjusted to $\mathrm{pH} 7.2$ ). Experiments were carried out at $15^{\circ} \mathrm{C}$.

TORPEDO: Slices of four to six adjacent electrogenic prisms were dissected from the electric organ of Torpedo marmorata previously chilled for $15 \mathrm{~min}$ on ice. They were soaked in a solution containing in $\mathrm{mM}: \mathrm{NaCl}, 280 ; \mathrm{KCl}, 3 ; \mathrm{CaCl}_{2}, 3.4 ; \mathrm{MgCl}_{2}$, 1.8; sodium phosphate buffer, $1.2(\mathrm{pH} 6.8)$ : glucose, 5.5 ; urea, 300 ; sucrose, 100. After equilibration with $\mathrm{O}_{2}, 4-5 \mathrm{mM} \mathrm{NaHCO}_{3}$ was added to adjust the $\mathrm{pH}$ to 7-7.1. Experiments were carried out at room temperature $\left(18^{\circ}-22^{\circ} \mathrm{C}\right)$.

\section{Electrophysiological Recordings}

The preparations were pinned on elastomere in a small (2-ml) Perspex chamber continuously perfused with fresh physiological solution described in the previous section. Intracellular records were made through 5-10 $\mathrm{M} \Omega$ microelectrodes filled with $3 \mathrm{M}$ $\mathrm{KCl}$. In the case of torpedo electroplaques, extracellular recordings from superficial nerve terminals of the ventral face were also obtained through larger microelectrodes made by blunting the broken tip on a microforge. These electrodes were filled with the torpedo physiological solution and had a resistance of $1-2 \mathrm{M} \Omega$.

After stabilization of the recordings for at least $30 \mathrm{~min}$, the venom (10-200 $\mu$ l of the concentrated solution) was added to 20 $\mathrm{ml}$ of the physiological solution, giving a final concentration of $0.01-0.2$ gland $/ \mathrm{ml}$. This solution, continuously recycled, was then used for perfusion. During prolonged experiments, the total circulating solution was replaced every $3 \mathrm{~h}$ with $20 \mathrm{ml}$ of fresh solution containing the same venom concentration, to minimize hyperosmotic effects resulting from evaporation. The electrical activity was monitored on an oscilloscope and on a pen chart recorder (Brush 2400, Gould Inc.. Cleveland. Ohio). Samples of activity were also recorded on a cassette magnetic recorder (Minilog 4, Philips. Eindhoven, The Netherlands) with a band pass of $0-5 \mathrm{kHz}$ for further processing.

\section{Numerical Processing of Electrical Recordings}

To obtain numerical estimations of the venom effect, the number of miniature potentials was automatically evaluated during successive time intervals of equal duration. The intracellular activity stored on magnetic tape was filtered with a narrow band-pass filter in the range of $1-3 \mathrm{kHz}$. The output of the filter was connected to a trigger giving standard pulses that were counted and stored on a Didac 800 signal processor (Intertechnique, Plaisir, France). This method allowed good separation of the miniature potentials occurring even at very short intervals. In the preliminary experiments, analysis of control samples was done by hand and gave results similar to those obtained by automatic processing. 


\section{Biochemical Methods}

The biochemical measurements were carried out on torpedo electric organ.

eValuation of transmitter release: Samples of three to four adjacent electrogenic prisms, tied at one end by a thread, were incubated for $1 \mathrm{~h}$ in physiological solution containing $\left[1-{ }^{14} \mathrm{C}\right]$ acetate, $2 \mu \mathrm{Ci} / \mathrm{ml}$ (specific activity: $58 \mathrm{mCi} / \mathrm{mmol}$ ) The solution also contained $0.1 \mathrm{mM}$ choline chloride. The radioactive acetate was then washed for $1.75 \mathrm{~h}$ in $150 \mathrm{ml}$ of physiological solution, changed once. The samples were then hung and superfused with a flow of physiological solution, guided by the thread, until a low and stable radioactive efflux was obtained. The venom was then added to the perfusion. Three drops of the perfusate were collected every $30 \mathrm{~s}$ in a vial. After the addition of $2 \mathrm{ml}$ of ethanol and scintillation mixture (toluene, Triton $\mathrm{X}$ 100, PPO, and POPOP), the radioactivity was counted in a scintillation counter.

Acetate was used in the present work because it was shown to be an excellent acetylcholine precursor in torpedo electric organ, most of the radioactivity incorporated in the nerve terminal being found as acetylcholine $(22,29)$. The increased efflux of acetate triggered by nerve stimulation was shown to be $\mathrm{Ca}$ dependent. similar to the increased choline efflux when the choline moiety of $\mathrm{ACh}$ was labeled $(12,21)$

Evaluation of aceTYlCHOLINE CONTENTS: Samples of $0.3-0.4 \mathrm{~g}$ of tissue were extracted in 5\% TCA. After ether washes to $\mathrm{pH} 4$, acetylcholine was assayed by the conventional frog rectus method (26). Total and bound $\mathrm{ACh}$ were determined for an evaluation of the vesicular and cytoplasmic pools of transmitter (11).

\section{Morphological Methods}

Frog muscles were fixed with $2 \%$ glutaraldehyde (previously neutralized with $\mathrm{NaOH}$ ) in $0.1 \mathrm{M}$ sodium cacodylate buffer $(\mathrm{pH}$ 7.4) for $1.5 \mathrm{~h}$. After washing with the same buffer containing 0.2 $M$ saccharose for $10 \mathrm{~min}$, the muscles were postfixed with $2 \%$ $\mathrm{OsO}_{4}$ in sodium cacodylate buffer for $1 \mathrm{~h}$.

The same procedure was used for crayfish muscles, except that sodium cacodylate was used at a concentration of $0.125 \mathrm{M}$ Small pieces of electric organ were fixed for $1.5 \mathrm{~h}$ with $3 \%$ glutaraldehyde (neutralized with $\mathrm{NaOH}$ ) in $0.4 \mathrm{M}$ sodium cacodylate ( $\mathrm{pH} 7.3$ ), washed for $10 \mathrm{~min}$ in $0.4 \mathrm{M}$ sodium cacodylate containing $0.3 \mathrm{M}$ saccharose, and postfixed in $2 \% \mathrm{OsO}_{4}$ in $0.4 \mathrm{M}$ sodium cacodylate buffer.

In all cases, the samples were dehydrated in ethanol and embedded in Spurr's resin. Thin sections were stained with uranyl acetate and lead citrate. For each type of preparation, both control and venom-treated samples were incubated and fixed in parallel.

\section{RESULTS}

We studied mainly the effect of Glycera venom (GV) on the cutaneous pectoris muscle of the frog. This thin preparation permits rapid access of substances and was extensively used to study the effects of other venoms. Experiments performed on other preparations will also be reported. They were carried out on crayfish neuromuscular preparations in which acetylcholine $(\mathrm{ACh})$ is not a neurotransmitter and on torpedo electric organ, a cholinergic preparation that permits easy biochemical measurements.

\section{Effect of GV on the Frog Neuromuscular Preparation}

In all of the 10 independent experiments carried out on cutaneous pectoris muscles, the treatment with GV (0.05-0.2 gland $/ \mathrm{ml})$ led to an important increase in the frequency of miniature end-plate potentials (mepp). After a latency of 1-2 min after the beginning of the venom perfusion, the first effect appears as a short burst of mepp (Fig. 1, end of trace $B$ ). Longer bursts occur in the following seconds (Fig. 1, $C$ ) until a sustained activity of mepp sets up (Fig. $1, D$ and $E$ ). This activity (mean mepp frequency in the range of 50-100/s) can be observed for many hours. In an experiment where the GV effects were continuously monitored in the same preparation for $19 \mathrm{~h}$, this activity was clearly found in all fibers examined after $15 \mathrm{~h}$ of venom action (Fig. 2). After 19-20 h, an abnormally high activity was still observed in some fibers, other ones being almost silent.

To describe the parameters of the sustained mepp discharge triggered by $\mathrm{GV}$, we estimated the mean frequency during successive $5 \mathrm{~s}$ periods at different times throughout the experiment. Fig. 3 shows that the mepp frequency remains roughly constant around $50 / \mathrm{s}$. Bursts of high frequency (up to $150 / \mathrm{s}$ ) as well as periods of relatively low frequency $(20 / \mathrm{s})$ occur in an unpredictable way.

Except for the phasic depolarization induced by the summation of the high-frequency mepp, no significant change in the muscle membrane potential was noticeable after venom application. For example, a value of $89 \mathrm{mV} \pm 5.9 \mathrm{SD}(n=21)$ was found in a muscle treated for $3 \mathrm{~h}$ with a solution containing the equivalent of 0.1 gland $/ \mathrm{ml}$. The venom effect was not modified when GV was applied in the presence of $12-\mu \mathrm{M}$ tetrodotoxin after 20 -min preincubation with this agent and verification of its blocking effect. On the other hand, curare $\left(10^{-5} \mathrm{M}\right)$ immediately abolished the electrical activity in the muscle fiber, which then hyperpolarized by $\sim 1 \mathrm{mV}$.

\section{Reversibility of GV Action on Frog Cutaneous Pectoris}

When the action of GV was allowed to develop over several 10 -min observation periods, it was 


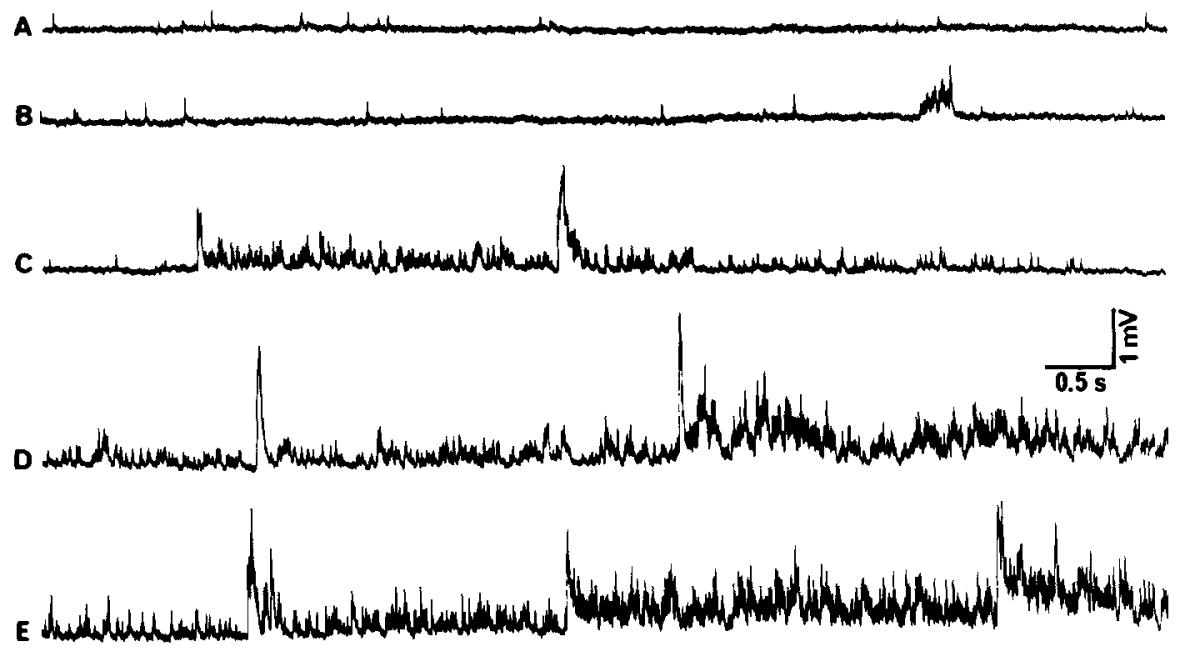

FIGURE I Effect of $G V$ on the spontaneous quantal release in a cutaneous pectoris muscle fiber. $(A)$ Background control activity. $(B)$ An isolated burst appeared $85 \mathrm{~s}$ after the start of venom perfusion. $(C)$ A longer burst at $105 \mathrm{~s}$. ( $D$ and $E$ ) Samples of sustained activity observed after $140 \mathrm{~s}$ and $14 \mathrm{~min}$, respectively. Pen chart recordings, obtained from magnetic tape recordings replayed at low speed. In this experiment, the crude venom extract was gel filtered on Sephadex G-50. The final concentration of venom corresponds to $\sim 0.05$ gland $/ \mathrm{ml}$.

A
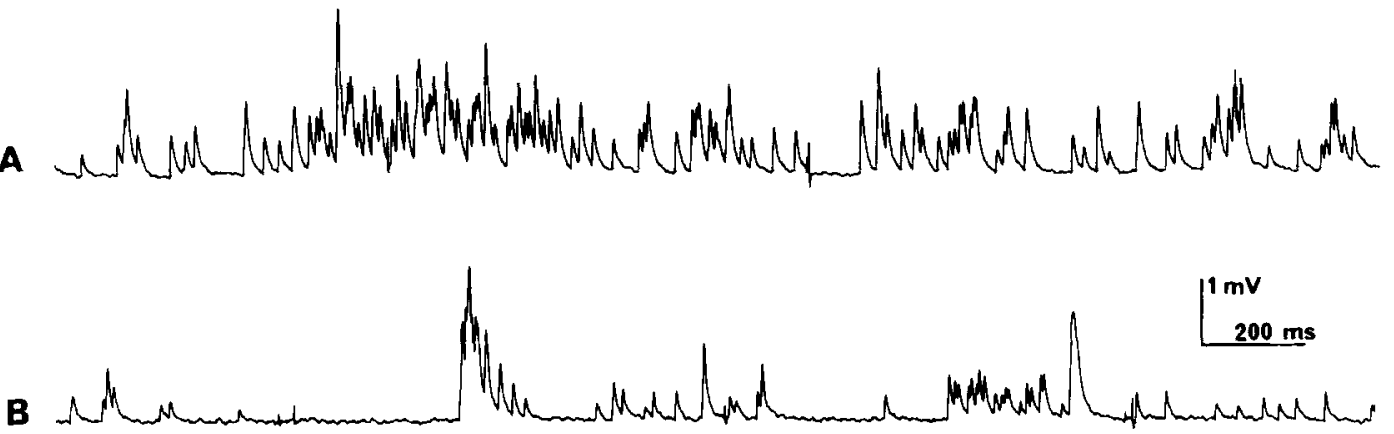

Figure 2 Intracellular recordings of the spontaneous quantal release from two different fibers of frog cutaneous pectoris muscle treated for $15 \mathrm{~h}$ with a solution containing $\mathrm{GV}(0.1 \mathrm{gland} / \mathrm{ml})$. Recordings as in Fig. 1.

still possible to obtain an almost complete reversal of the effect by washing with venom-free solution. An example is shown in Fig. 4. The venom effect, developed after a 2-min latency, was observed for $20 \mathrm{~min}$, then the preparation was washed. The mepp frequency decreased and within $10 \mathrm{~min}$ reached a level roughly comparable to the control level. In four other experiments in which the preparations were washed after up to $3 \mathrm{~h}$ of venom action, a marked decrease of the mepp frequency was observed and the effect resumed after further addition of venom.

\section{Ultrastructure of Nerve Terminals of Frog Cutaneous Pectoris Treated With GV}

The observations were made after either 5 or 19 $h$ of venom action. The venom concentrations, respectively, were 0.05 and 0.1 gland $/ \mathrm{ml}$, which gave the usual high-frequency mepp activity continuously monitored by electrophysiological methods.

After $5 \mathrm{~h}$, no obvious change was noticed in the 25 terminals examined (Fig. 5). The number of synaptic vesicles was equivalent in both control 


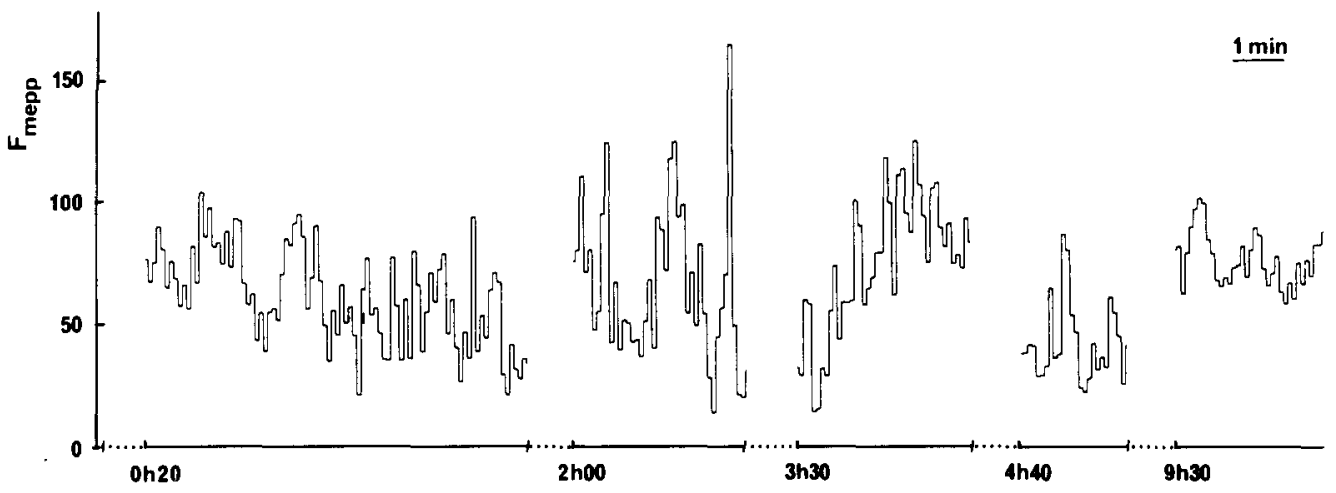

FigURE 3 Mepp frequency vs. time of GV action. The mepp frequency was estimated during successive $5 \mathrm{~s}$ periods at different stages of the experiment. Data from the same fiber of a cutaneous pectoris muscle. Time on the abscissa refers to the duration of venom action. The venom concentration corresponds to 0.1 gland $/ \mathrm{ml}$.

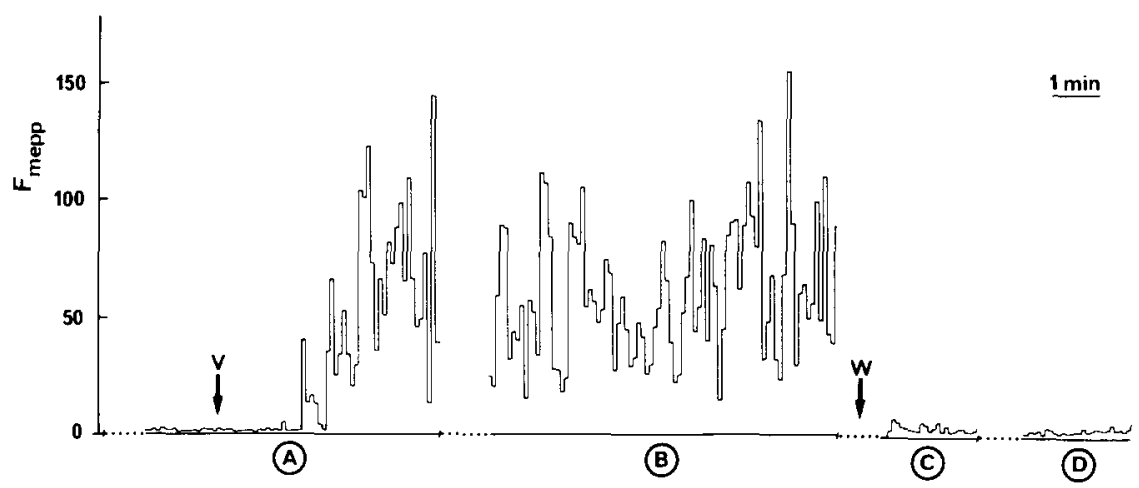

Figure 4 Reversibility of the venom effect. As in Fig. 3, the mepp frequency was estimated during successive $5 \mathrm{~s}$ periods. $(A)$ Onset of the GV effect; the venom $(V)$ was added at the arrow. $(B)$ Full effect of the venom before washing $(W)$. ( $C$ and $D$ ) Mepp frequency after 10-min $(C)$ and 22-min $(D)$ washing. Same fiber as in Fig. 1.

and treated preparations. In some cases (Fig. $5 b$ ), their distribution seemed slightly different from that of the control, in which vesicles appeared more evenly distributed. However, in other terminals, no change in their distribution could be found. The mitochondria, the nerve terminal membrane, and the synaptic cleft were not modified.

After $19 \mathrm{~h}$, most of the terminals were strongly modified (Fig. 6). In 24 of 26 terminals examined, the nerve terminal was invaded by numerous membrane invaginations, leading more or less to a fragmentation of the cytoplasm. Synaptic vesicles were still present but varied more in size. Many mitochondria were swollen or even destroyed and identifiable only by crest fragments. However, in the other two terminals examined, the synaptic vesicle population looked roughly normal, whereas some mitochondria were extremely swollen. In all cases, no modification of the synaptic cleft was observed.

\section{Effect of GV on Crayfish Neuromuscular Preparations}

To test the effect of GV on a simple noncholinergic preparation, we carried out some experiments on crayfish muscles. Those muscles are multiply innervated by excitatory and inhibitory axons; the putative neurotransmitters involved are, respectively, L-glutamate and gamma-amino-butyric acid (references in 2). An effect similar to that obtained in the frog was found in four dactyl opener preparations with concentrations in the 

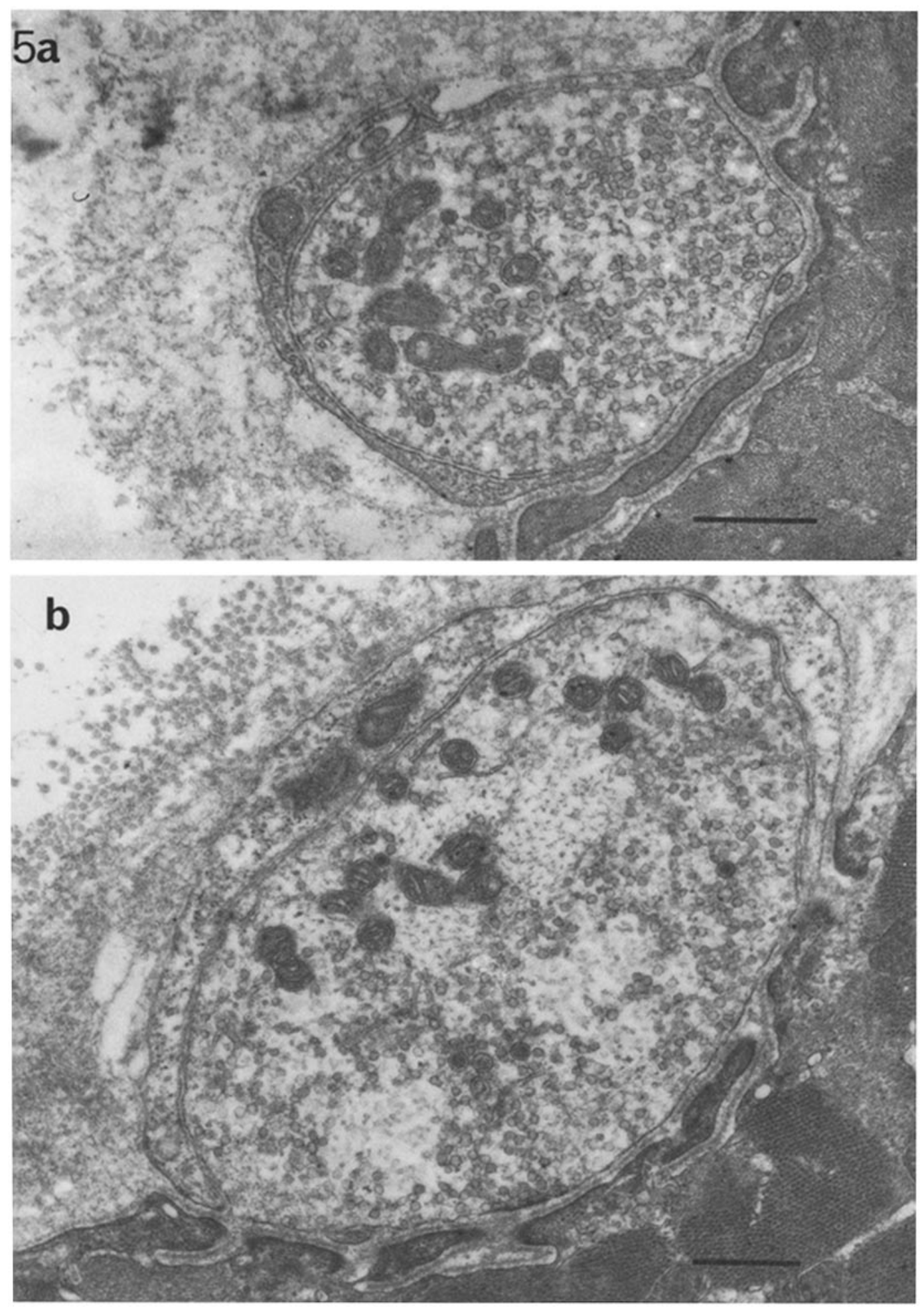

FIGURE 5 Cross sections of frog neuromuscular junctions. (a) Control preparation. Bar, $0.5 \mu \mathrm{m} \times 38,000$. (b) Preparation treated for $5 \mathrm{~h}$ with GV $(0.05 \mathrm{gland} / \mathrm{ml})$. It is comparable to the control. Bar, $0.5 \mu \mathrm{m}$. $\times 33,000$. 


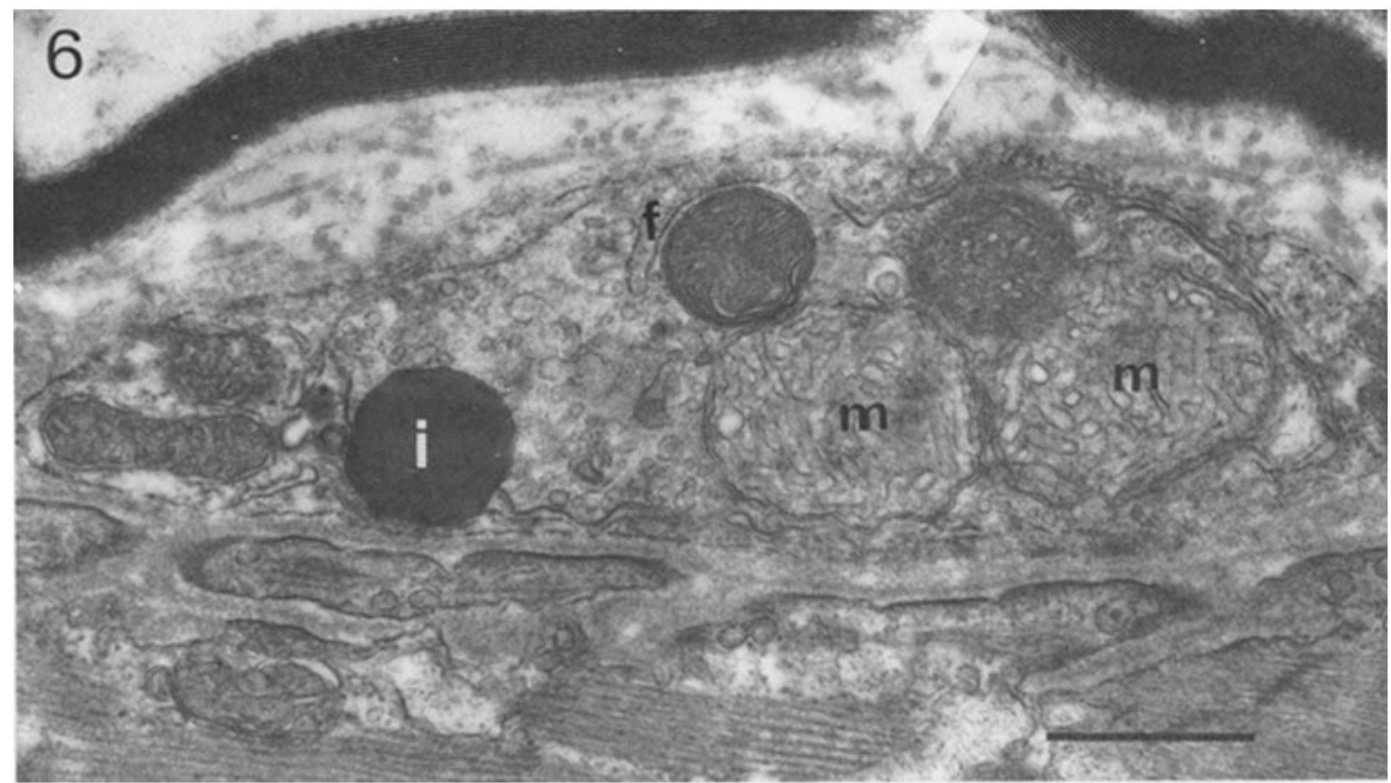

FIGURE 6 Frog neuromuscular junctions treated for $19 \mathrm{~h}$ with GV $(0.1$ gland $/ \mathrm{ml})$. Representative nerve terminal, showing lysosomelike inclusion $(i)$, vesicles, swollen mitochondria $(m)$, fingerlike invagination $(f)$ of Schwann cell. Bar, $0.5 \mu \mathrm{m} . \times 42,000$.

range of $0.01-0.2$ gland $/ \mathrm{ml}$. For the lowest concentration, we observed only brief isolated bursts similar to those seen at the onset of the GV effect in the frog. For higher concentrations, a sustained high-frequency discharge of miniature potentials was observed after a latency of about $100 \mathrm{~s}$ (Fig. 7). This high frequency of spontaneous activity, of the same order of magnitude as that observed in the frog, was maintained for $10-30 \mathrm{~min}$; it slowly decreased during the following hours but remained much above the control level.

In the crayfish, the venom action was characterized by two other features. First, giant spontaneous potentials of high amplitude (up to $15 \mathrm{mV}$ ) and long duration appeared shortly after the onset of the high-frequency miniature discharge. Samples of those giant potentials are shown in the inset of Fig. 7. No inflexion occurred on their rising phase, whereas, in the frog, analogous potentials clearly resulted from the summation of elementary events detectable on the rising phase. They occurred at maximum frequency $\sim 1 \mathrm{~h}$ after venom addition. Their frequency then decreased, but some were still occasionally seen after several hours. Similar "giant miniature potentials" have been observed in lobster preparations treated with BWSV (23)

Second, a tonic depolarization always developed simultaneously with the effect on miniature potentials. For a concentration of $0.025-0.05$ gland $/ \mathrm{ml}$, the muscle fiber depolarized in a first step by $\sim 5$ $\mathrm{mV}$ in 5-6 min, then gradually depolarized much more slowly in a second step during the following hours to a final value $\sim 10 \mathrm{mV}$ above the control resting potential.

Similar results were obtained on the fast posterior abdominal flexor (seven preparations tested). This preparation is less convenient for such a study because no spontaneous miniature potentials can be observed under normal conditions. However, after venom application, a short (2-4 min) burst of high-frequency potentials occurred during the first step of the depolarization. Large, isolated, spontaneous potentials are also observed but their amplitude is smaller than that of the dactyl opener giant potentials (maximum, $2 \mathrm{mV}$ ). After $\sim 2 \mathrm{~h}$ the muscle fibers slowly begin to repolarize even in the presence of venom.

On two occasions, GV was applied to fast posterior abdominal flexors denervated by axotomy 8 mo previously, in which nerve terminal degeneration was controlled by electrophysiological criteria (32). In those muscles, neither bursts of small potentials nor tonic depolarization were observed, whereas they were clearly seen in the correspond- 


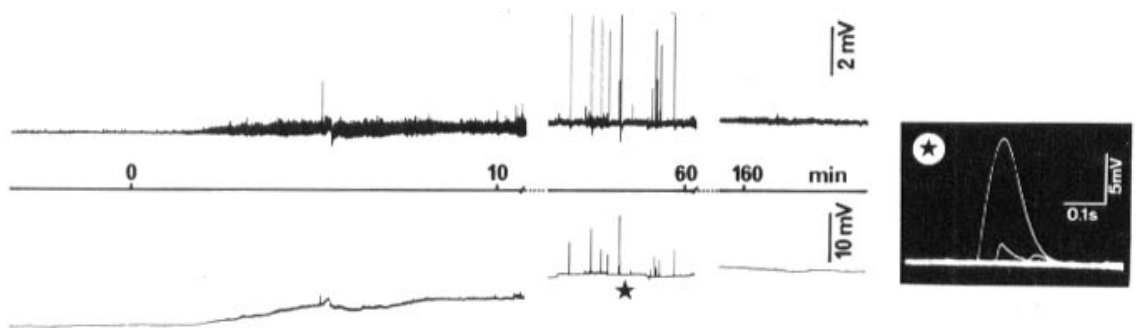

FIGURE 7 Effect of GV on the dactyl opener muscle of the crayfish. Samples of AC (upper trace) and DC (lower trace) recordings of the intracellular activity of one fiber at different times. The GV, at a concentration of 0.025 gland $/ \mathrm{ml}$, was introduced into the perfusion solution at time 0 . The second sample depicts the phase of most frequent occurrence of giant spontaneous potentials. Three of them are shown on the free-running oscilloscope record given in inset.
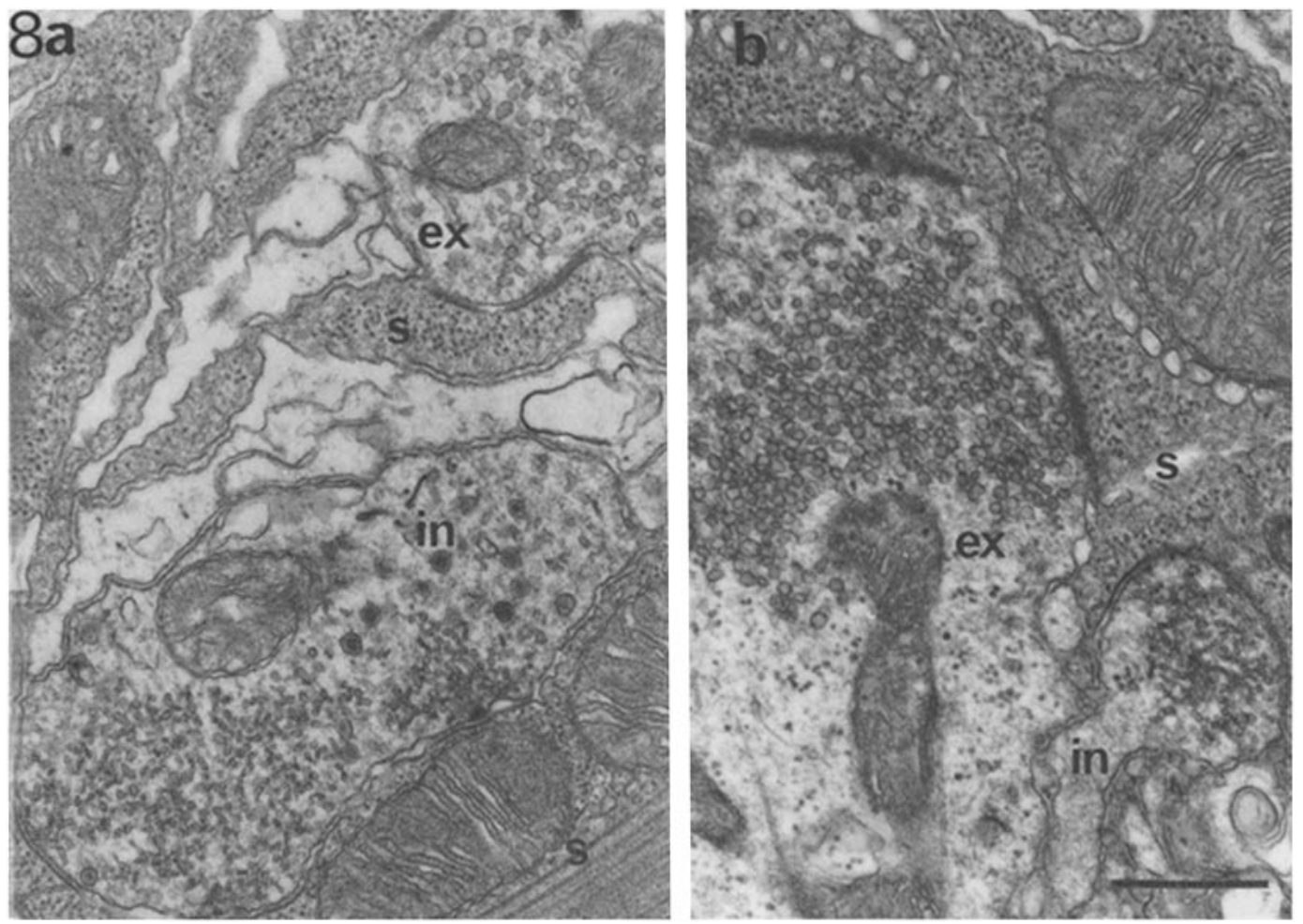

Figure 8 Crayfish neuromuscular junction. Bar, $0.5 \mu \mathrm{m} . \times 44,000$. (a) Control. (b) Preparation treated for $3 \mathrm{~h}$ with $\mathrm{GV}(0.025 \mathrm{gland} / \mathrm{ml})$. No detectable structural changes were observed in the inhibitory terminal (in) nor in the excitatory terminal (ex). s, sarcoplasm.

ing muscle of the previous segment taken as a control and simultaneously recorded in the same chamber.

The preparations were fixed $3 \mathrm{~h}$ after venom application, at a concentration of 0.025 gland $/ \mathrm{ml}$. At that time, the phase of maximum rate of discharge was over, but spontaneous activity was still higher than the control level and rare giant spontaneous potentials occasionally occurred. Both excitatory and inhibitory nerve terminals, which can be identified by their vesicle population (2), were examined. Surprisingly, no ultrastructural alterations were observed (Fig. 8). The number and shape of vesicles are comparable in treated and 
control samples. The mitochondria are not swollen and the synaptic cleft is unchanged.

\section{Effects of GV on Torpedo Nerve Electroplaque Preparations}

After a latency of $\sim 1 \mathrm{~min}$, the perfusion of electroplaques with a solution containing $0.1-0.2$ gland/ml of GV induced an important increase in the frequency of extracellularly recorded miniature potentials (Fig. 9). The activity reached its maximum after 4-5 min, then declined more slowly during the following $20-40 \mathrm{~min}$. After that time, some giant spontaneous potentials occurred and after about $100 \mathrm{~min}$ the effect was over.

In one experiment in which we recorded the intracellular activity of a surface electroplaque, we observed a depolarization of $15 \mathrm{mV}$ to be simultaneous with the rising phase of the high-frequency miniature activity. A progressive repolarization was synchronous with the decrease of the effect. The time-course of the intracellular response was similar to that of the DC record of the extracellular activity shown in Fig. 9. The relationship between the frequency of miniature potentials and the membrane potential suggests that the intracellularly recorded depolarization results from the summation of individual events. With the torpedo electroplaque preparation, we could verify that the release of transmitter estimated by the efflux of labeled acetate paralleled the activity of the miniature potentials. The time-course of both rising and falling phases of the radioactive efflux curve (Fig. 10) were comparable to those of the electrically recorded phenomenon. Three independent experiments, in which two samples were treated in parallel, gave similar results.
Attempts were made to determine whether the venom depleted $\mathrm{ACh}$ tissue stores. Because the penetration of the venom into the prisms is probably slow, incubations with $0.1-0.2 \mathrm{gl} / \mathrm{ml}$ solutions were performed for up to $4 \mathrm{~h}$ using small (0.3-0.4 g) samples of tissue. No significant change occurred either in the vesicular bound pool or in the free i.e., cytoplasmic, pool (bound: $103 \pm 3 \%$, free: $90 \pm 7 \%$ of the control values; $n=7$ ).

All of the samples examined by electron microscopy were taken from surface electroplaques. Preparations treated with venom were kept for 1$3 \mathrm{~h}$ in solutions containing 0.15 gland $/ \mathrm{ml}$. The

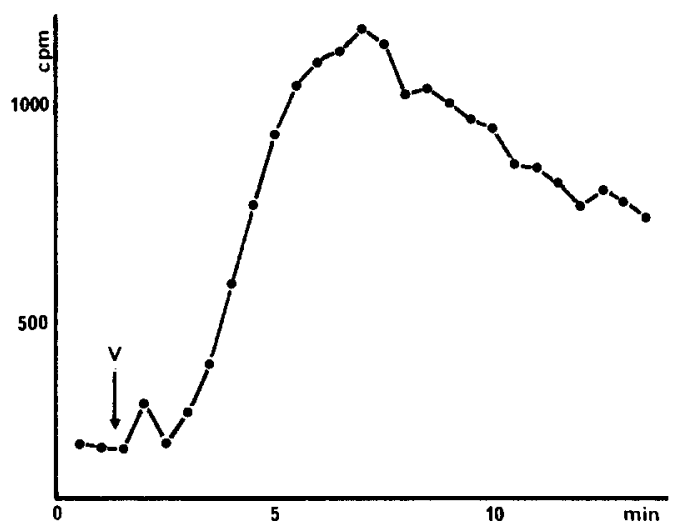

FIGURE 10 Effect of GV on ACh release from torpedo electric organ. The release was measured by the efflux of radioactive acetate. Torpedo electric organ prisms were perfused after labeling $\mathrm{ACh}$ tissue stores with $\left[1-{ }^{14} \mathrm{C}\right]-$ acetate. When the background radioactivity was low and constant, venom $(V)$ was added to the perfusion at a concentration equivalent to 0.1 gland $/ \mathrm{ml}$. This triggered a 10 -fold rise of radioactive efflux. The peak was reached in $5 \mathrm{~min}$, then the radioactivity gradually decreased.

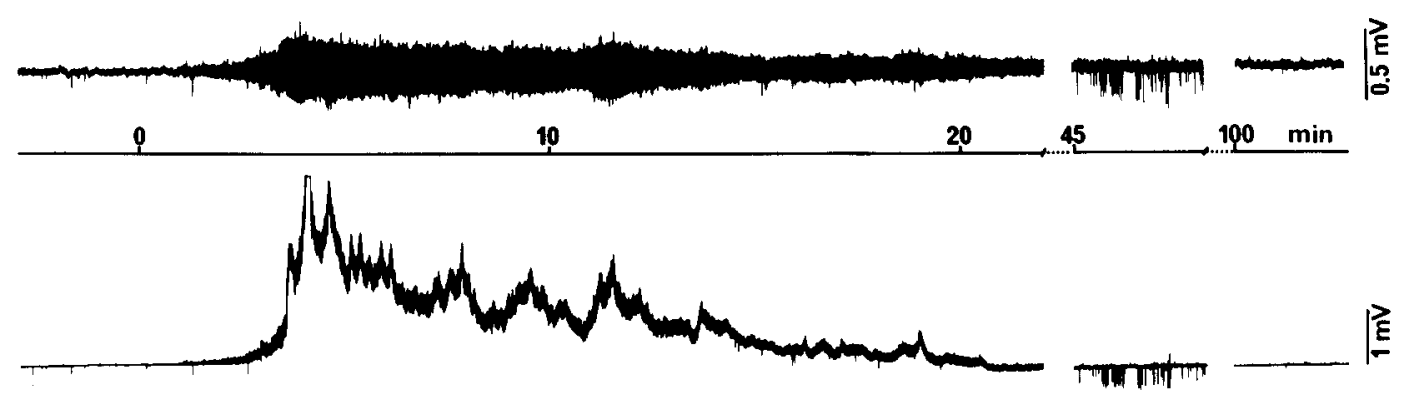

FIgURE 9 Effect of GV on a nerve electroplaque preparation. The electrical activity of a synaptic region was recorded through an extracellular electrode from a surface electroplaque and monitored on AC (upper trace) and DC (lower trace) channels of a pen chart recorder. The GV, at a concentration of 0.1 gland $/ \mathrm{ml}$, was introduced into the perfusing solution at time 0 . The miniature activity reached a maximum after $\sim 5$ min, then gradually decreased. A burst of giant isolated potentials was observed after 45 min of venom action. No activity was detectable after $70 \mathrm{~min}$. 

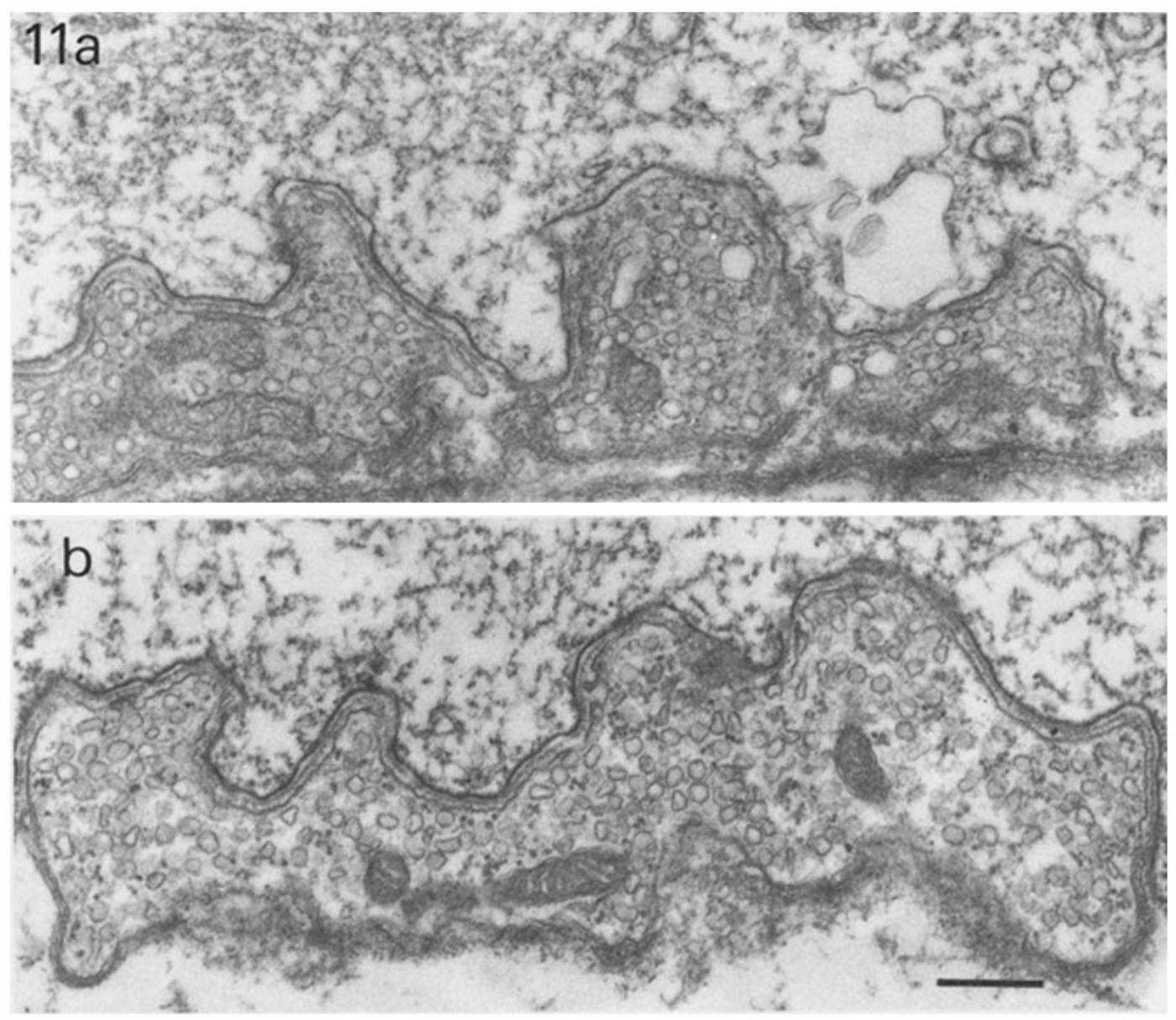

FigURE 11 Torpedo nerve-electroplaque junctions. Bar, $0.5 \mu \mathrm{m} . \times 26,000$. (a) Control. (b) Preparation treated for $3 \mathrm{~h}$ with GV $(0.1$ gland $/ \mathrm{ml})$.

number and distribution of synaptic vesicles were comparable in control and treated preparations (Fig. 11). No swelling of mitochondria and no modifications of the presynaptic membrane or of the synaptic cleft were observed.

\section{Calcium Dependence of GV Action}

When cutaneous pectoris muscles were soaked in a solution from which calcium was omitted, addition of GV did not produce any detectable effect. Upon calcium addition, the venom effect immediately developed. When $5 \mathrm{mM} \mathrm{Co}^{++}$was added to the perfusing solution, the mepp frequency clearly decreased and further addition of $5 \mathrm{mM} \mathrm{Ca}^{++}$resulted in a strong increase in the rate of discharge.

Further evidence of the calcium dependence of $\mathrm{GV}$ effect was drawn from the measurement of transmitter release from torpedo electric organ by the same method as that used in Fig. 10. Addition of GV in the solution superfusing the tissue previously equilibrated for $90 \mathrm{~min}$ in the absence of calcium was without effect (Fig. 12). When the normal calcium concentration $(3.4 \mathrm{mM})$ was restored, an immediate release occurred, even if the only venom present at that time was that impregnating the tissue (Fig. 12). If venom was maintained in the perfusion when calcium was added, the time-course of release was comparable to that of Fig. 11.

\section{DISCUSSION}

Several controls were judged necessary to eliminate the possibility of trivial artifacts. First, homogenates of different parts of Glycera body, skin, muscles, or gut, treated in the same way as the 


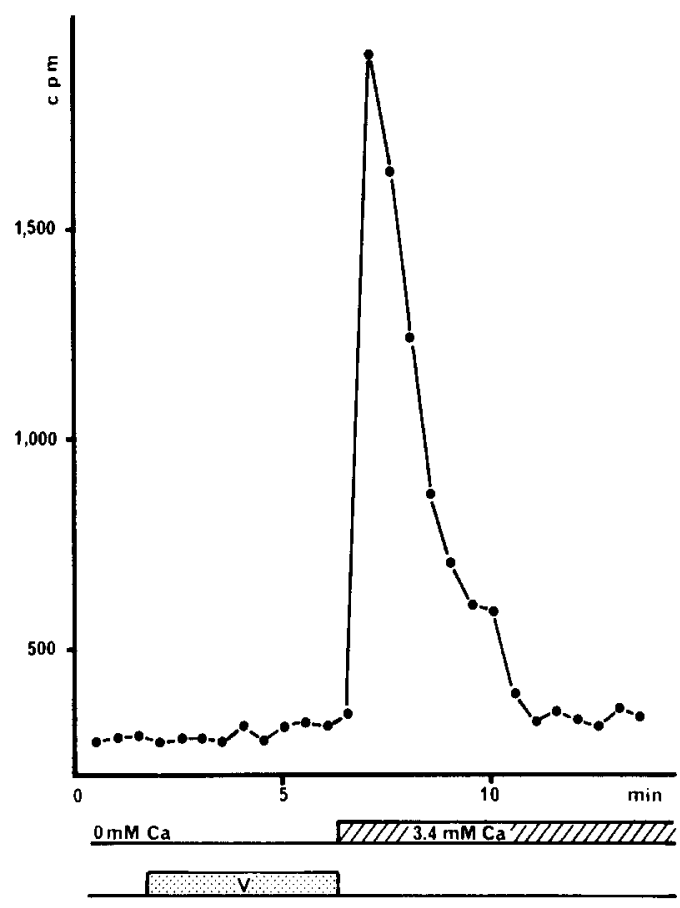

FigURE $12 \mathrm{Ca}$ dependence of transmitter release induced by $\mathrm{GV}$ in torpedo electric organ. We treated the preparation as described in Fig. 11, except that, after labeling and washing the precursor, we equilibrated the preparation for $90 \mathrm{~min}$ in a $\mathrm{Ca}^{++}$-free solution. Under these conditions, venom addition $(0.1 \mathrm{gland} / \mathrm{ml})$ was without effect. Immediately after restoration of the physiological $\mathrm{Ca}^{++}$concentration, a steep radioactive efflux occurred.

venom glands, were without effect when tested on frog cutaneous pectoris. Second, when the crude venom extract was treated for $5-10 \mathrm{~min}$ at $80^{\circ} \mathrm{C}$, it had no effect when tested on crayfish and frog preparations. Third, after gel filtration through Sephadex G-50, the venom activity was found in the excluded volume, thus implying that the effect is triggered by a high-molecular-weight component. Fourth, assays of the phospholipase activity of the extract (C. Bon, personal communication) permit us to consider the possibility that the effect does not result from phospholipase action. The above controls together with the reported results substantiate the existence in Glycera glands of a substance having the characteristics of a neurotoxin.

When applied to the frog neuromuscular junction, this substance obviously triggers an important increase in transmitter release, as judged by the frequency of mepp. An essential feature of this effect is that it persists for a very long time. Estimations of the number of quanta released after GV application can be drawn from experiments similar to that illustrated in Fig. 3. In this experiment, an average value of $\sim 50 \mathrm{mepp} / \mathrm{s}$ was observed in the same fiber during $>9 \mathrm{~h}$, leading to a figure of $\sim 1.6 \times 10^{6}$ quanta released during that time. Because, during the following hours frequencies 10-50 $\times$ higher than in the controls were observed, the above figure is an underestimate of the number of quanta released. At this stage, it is of interest to compare this estimation to those drawn from the study of BWSV on the same material (4). In the latter case, the total number of quanta released in $<1 \mathrm{~h}$ was in the range of $2.9-$ $7.4 \times 10^{5}$. Because the $\mathrm{GV}$ venom induces the release of at least four times that amount, several possible explanations can be put forward.

One explanation is that the number of quanta released until exhaustion of the BWSV effect is underestimated. This, however, seems unlikely, because estimations based on the results of Longenecker et al. (25) lead to comparable values. Another could be that BWSV does not induce the release of the total store; this seems also unlikely, because it leads to a full depletion of the nerve terminals (7). The most likely explanation is that GV venom does not impair the turnover of the release process and that several renewals of the store take place during prolonged venom application. A similar reason has been proposed to explain how $\mathrm{La}^{3+}$ applied to frog neuromuscular preparations causes the release of $3-5 \times 10^{6}$ quanta in a few hours (20). An important feature of GV action is its calcium dependence. Because it is now largely admitted that calcium entry into the nerve terminal triggers the release process (28), we can put forward the hypothesis that $\mathrm{GV}$ acts through a mechanism increasing the intraterminal $\mathrm{Ca}^{++}$ concentration. BWSV is known to induce calcium channels on lipid bilayers membranes (13). If the nerve terminal remains able to continuously buffer the entry of calcium, a steady state of increased mepp frequency can presumably be reached. A stable rate of discharge is indeed observed for $>5$ $\mathrm{h}$, and the morphological pictures examined after $5 \mathrm{~h}$ of $\mathrm{GV}$ action did not show any obvious modifications. At that time more than the initial store was released, whereas in the same situation BWSV led to a complete depletion of intraterminal organelles. None of the 25 terminals examined at that stage of GV action were different from their controls and, from this point of view, the two 
venoms appear different. However, small changes in the number or distribution of organelles cannot be ruled out. After $>10-15$ h of GV action, the electrical activity progressively subsides and some morphological alterations appear. These alterations are reminiscent, in some respects, of those observed after treatment with high $\mathrm{Ca}^{++}$solutions (19). Some terminals are fragmented and invaded by Schwann cell invaginations, and the mitochondria are swollen. At that stage, the calcium-buffering system might no longer operate. However, the mechanism by which $\mathrm{GV}$ would enhance $\mathrm{Ca}^{++}$ entry into the terminal remains to be established. A study of evoked release during venom action might give valuable information on this mechanism, and such a study is now in progress. Preliminary results indicate that after $18 \mathrm{~h}$ of $\mathrm{GV}$ action $(0.2$ gland $/ \mathrm{ml})$, the stimulation of motor axons still evoked junctional potentials in all frog muscle fibers, some large enough to trigger muscle action potentials. That the effect of $\mathrm{GV}$ can be easily reversed by washing, at least during the first hour, makes it unlikely that the venom would be a $\mathrm{Ca}^{++}$ ionophore strongly bound to the membrane.

It should be noted, from preliminary observations, that the GV effect seems to be dose dependent, because for low concentrations it produces only isolated short bursts, and also that further addition of $\mathrm{GV}$ results in an increased effect. This effect is markedly different from that of BWSV, threshold concentrations of which produce the maximum effect and higher concentrations modify only the latency (25).

The experiments carried out on crayfish and torpedo demonstrated the nonspecificity of the crude extract. However, the time-course of the effect was different in those preparations. In the torpedo, the electrical effect stops after $\sim 1 \mathrm{~h}$. In the crayfish, the activity subsides after the initial burst but remains much higher than in the control for many hours. At present, it is impossible to know whether these differences result from the properties of the nerve terminals and transmitter stores or whether the crude extract contains several substances specific for the different preparations. Such a situation was recently demonstrated for BWSV; proteins active in lobster were not identical to those active in frog (14). Complete depletions of synaptic vesicles were generally reported to be concomitant with BWSV action. However, some observers have pointed out time discrepancies between the electrical effect and structural changes (6). After 1-2 h of BWSV action on the rat superior cervical ganglia, at a stage when transmission was already interrupted, the nerve endings did not show appreciable changes. Similarly, few modifications were observed on BWSV-treated torpedo electroplaque fractions (17). Finally, it was shown that after stimulation in the presence of hemicholinium, it was possible to deplete transmitter stores without affecting the vesicle population and to deplete, in a subsequent stage, the terminals from their vesicles by BWSV application (3). All these results favour a dual mode of action by BWSV (see also references 15 and 16). One component of this action would be responsible for the increased release; the other would lead in addition to ultrastructural modifications. GV seems to have an effect only on transmitter release without blocking the recovery process and perhaps will be, for this reason, a valuable tool for future studies of the release mechanisms.

We are grateful to Mr. B. Lesbats and Mrs. R. Charre for their efficient help.

This work was supported by grant A650.1525 from the Délégation Générale à la Recherche Scientifique et Technique.

Received for publication 25 July 1979, and in revised form 27 December 1979.

\section{REFERENCES}

1. ABE, T., A. R. LIMBRIC, and R. MiLeDI. 1976. Acute muscle denervation induced by $\beta$-bungarotoxin. Proc. R. Soc. Lond. B. Biol. Sci. 194:545553.

2. ATwoon, H. L. 1976. Organization and synaptic physiology of crustacean neuromuscular systems. Pro. Neurobiol. (Oxf.) 7:291-391.

3. Ceccarelli, B., and W. P. Hurlaut. 1975. The effects of prolonged repetitive stimulation in hemicholinium on the frog neuromuscular junction. J. Physiol. (Lond.). 247:163-188.

4. Ceccarelli, B., W. P. Hurlbut, and A. Malro. 1973. Turnover of transmitter and synaptic vesicles at the frog neuromuscular junction. $J$. Cell Biol. 57:499-524.

5. Chang, C. C., T. F. Chen, and C. Y. Lee. 1973. Studies of the presynaptic effect of $\beta$-bungarotoxin on neuromuscular transmission. J. Pharmacol. Exp. Ther. 184:438-444.

6. Chmovllovsky, M., Y. Dunant, J. Graf, R. W. Straub, and C. RLFENER. 1972. Inhibition of creatine phosphokinase activity and synaptic transmission by black widow spider venom. Brain Res. 44:289293.

7. Clark, A. W., W. P. Hurlbut, and A. Malro. 1972. Changes in the fine structure of the neuromuscular junction of the frog caused by black widow spider venom. J. Cell Biol. 52:1-14.

8. Clark, A. W., A. Mauro, H. E. Longenecker, and W. P. Hurlbut. 1970. Effects of black widow spider venom on the frog neuromuscular junction. Effects on the fine structure. Nature (Lond.) 225:703-705.

9. Cull-Candy, S. G., H. Neal. and P. N. R. Usherwood. 1973. Action of black widow spider venom on an aminergic synapse. Nature (Lond.). 241:353-354.

10. Dudel. J., and S. W. Klffler, 1961. The quantal nature of transmission and spontaneous miniature potentials at the crayfish neuromuscular junction. J. Physiol. (Lond.). 155:514-529.

11. Dunant, Y.. J. Gautron, M. Israel. B. Lesbats, and R. ManarANCHF. 1972. Les compartiments d'acétylcholine de l'organe électrique de la torpille et leurs modifications par la stimulation. J. Neurochem. 19:1987-2002.

12. Dunant, Y.., and M. IsRaei.. 1975. Acetylcholine turnover in the course 
of stimulation. In Cholinergic Mechanisms. P. G. Waser, editor. Raven Press, Inc., New York. 161-167.

13. Finkelstein, A., L. L. Rubin, and M. C. Tzeng. 1976. Black widow spider venom: effect of purified toxin on lipid bilayer membranes. Science (Wash. D. C.). 193:1009-1011.

14. Fritz. L. C. M. C. Tzeng, and A. MAuro. 1978. Different components of black widow spider venom mediate transmitter release at vertebrate and crustacean neuromuscular junctions. Soc. Neurosci. Symp. 4:369 (Abstr.).

15. Gorto, A., and A. Mauro. 1979. Reversibility and mode of action of black widow spider venom on the vertebrate neuromuscular junction. J. Gen. Physiol. 73:245-263.

16. Gorio, A., L. L. Rubin, and A. Mauro. 1978. Double mode of action of black widow spider venom on frog neuromuscular junction. $J$ of black widow spider

17. Granata, F., M. E. Traina, N. Frontali, and B. Bertolini. 1974 Effects of black widow spider venom on acetylcholine release from torpedo electric tissue slices and subcellular fractions in vitro. Comp. Biochem. Physiol. 48A: L-7.

18. HALSTEAD, B. W. 1965. Poisonous and venomous marine animals of the world. Vol. I. U. S. Government Printing Office, Washington, D. C.

19. Heuser. J., B. Katz, and R. Milede. 1971. Structural and functional changes of frog neuromuscular junctions in high calcium solutions. Proc. R. Soc. Lond. B. Biol. Sci. 178:407-415.

20. HeLSER, J., and R. MiLEDI. 1971. Effect of lanthanum ions on function and structure of frog neuromuscular junctions. Proc. R. Soc. Lond. Biol. Sci. 179:247-260.

21. IsRael, M., and Y. DUNANT. 1975. Dynamics of acetylcholine compartments at rest and during nerve activity. In Metabolic Compartmentation and Neurotransmission S. Berl, D. D. Clarke, and D. S. Schneider, editors. Plenum Press Corp., New York. 621-639.

22. ISRAEL, M.. and S. TŬCEK. 1974. Utilization of acetate and pyruvate for the synthesis of "total", "bound" and "free" acetylcholine in the electric organ of torpedo. J. Neurochem. 22:487-491

23. Kawai, N., A Matro, and H. Grundfest. 1972. Effect of black widow spider venom on the lobster neuromuscular junctions. $J$. Gen. Physiol. 60:650-665.

24. KIAWE, W L and L. H. Dirkif 1957. Biology of the bloodworm Glycera dibranchiata Ehlers and its relation to the bloodworm fishery of the Maritime Provinces. Bull. Fish. Res. Board Can. 115:1-136.

25. Longenecker. H. E., W. P. Hurlbut, A. Mauro, and A. W. Cl.ark 1970. Effects of black widow spider venom on the frog neuromuscular junction. Effects on end-plate potential, miniature end-plate potential and nerve terminal spike. Nature (Lond.). 225:701-703.

26. MCINTosh, F. C., and W. L. M. Perry. 1950. Biological estimation of acetylcholine. Methods Med. Res. 3:78-92.

27. MICHEL, C. 1966. Mächoires et glandes annexes de Glycera convoluta (Keferstein), annelide polychète glyceridae. Cah. Biol. Mar. 7:367-373.

28. MILEDI. R. 1973. Transmitter release induced by injection of calcium ions into nerve terminals. Proc. R. Soc. Lond. B Biol. Sci. 183:421-425.

29. Morel, N., M. Israel. R. Manaranche, and P. Mastour-Frachon. 1977. Isolation of pure cholinergic nerve endings from torpedo electric organ. Evaluation of their metabolic properties. J. Cell Biol. 75:43-55.

30. Selverston, A. I., and M. P. Remler. 1972. Neural geometry and activation of crayfish fast flexor motoneurons. J. Neurophysiol. (Bethesda) 35:797-814.

31. Spira, M. E., M. Klein, B. Hochner. Y. Yarom, and M. Castel 1976. Ultrastructure changes accompanying the disturbances of neuromuscular transmission caused by Pardachirus toxin. Neuroscience. 1: $117-124$.

32. ThigfFry, M. J. Bruner, and P. Personne, 1979. The presynaptic action of L-glutamate at the crayfish neuromuscular junction. Results obtained by intraaxonal recordings and nerve terminal damage. $J$. Physiol. (Paris). 75:635-639. 